\title{
Effect of school-based physical activity interventions on body mass index in children: a meta-analysis
}

\author{
Kevin C. Harris MD, Lisa K. Kuramoto MSc, Michael Schulzer MD PhD, Jennifer E. Retallack MD
}

$\infty \quad$ See related commentary by Baur, page 701

\section{ABSTRACT}

Background: The prevalence of childhood obesity is increasing at an alarming rate. Many local governments have enacted policies to increase physical activity in schools as a way to combat childhood obesity. We conducted a systematic review and meta-analysis to determine the effect of school-based physical activity interventions on body mass index (BMI) in children.

Methods: We searched MEDLINE, EMBASE, CINAHL and the Cochrane Central Register of Controlled Trials up to September 2008. We also hand-searched relevant journals and article reference lists. We included randomized controlled trials and controlled clinical trials that had objective data for BMI from before and after the intervention, that involved school-based physical activity interventions and that lasted for a minimum of 6 months.

Results: Of 398 potentially relevant articles that we identified, 18 studies involving 18141 children met the inclusion criteria. The participants were primarily elementary school children. The study duration ranged from 6 months to 3 years. In 15 of these 18 studies, there was some type of cointervention. Meta-analysis showed that BMI did not improve with physical activity interventions (weighted mean difference $-0.05 \mathrm{~kg} / \mathrm{m}^{2}, 95 \%$ confidence interval -0.19 to $0.10)$. We found no consistent changes in other measures of body composition.

Interpretation: School-based physical activity interventions did not improve BMI, although they had other beneficial health effects. Current population-based policies that mandate increased physical activity in schools are unlikely to have a significant effect on the increasing prevalence of childhood obesity.

Une version française de ce résumé est disponible à l'adresse www.cmaj.ca/cgi/content/full/180/7/719/DC1

CMAJ 2009;180(7):719-26

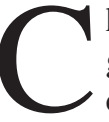
hildhood obesity is a major public health problem, given its increasing prevalence and adverse health consequences. ${ }^{1}$ In the United States, the prevalence of obesity among children, defined as body mass index (BMI) greater than or equal to the 95th centile, has more than tripled since 1970.,3 The proportion of children 6 to 11 years old exceeding the 95th centile increased from $4.0 \%$ in 1971-1974 to $18.8 \%$ in 2003-2004, and the proportion of obese adolescents
(12 to 19 years of age) increased from $4.6 \%$ in $1966-1970$ to $17.4 \%$ in 2003-2004. ${ }^{2,3}$ Similar trends have been observed in Canada, ${ }^{4}$ the United Kingdom ${ }^{5}$ and Europe. ${ }^{6}$ In addition to the growing numbers of obese children, the proportions of children with BMI greater than the 10th, 50th, 85th and 90th centiles continue to increase, which indicates an increase in weight for height across the entire population. ${ }^{2,7}$ These trends are likely to result in significant increases in the rates of coronary artery disease, hypertension, diabetes mellitus and other obesity-related diseases in young and middle-aged adults. ${ }^{8-10}$ This in turn may result in the first-ever decline in life expectancy in the developed world. ${ }^{11}$

Reversing the trend of increasing weight for height in children has proven difficult. It is widely accepted that increasing energy expenditure and reducing energy intake form the theoretical basis for management. Therefore, interventions aiming to increase physical activity and improve diet are the foundation of efforts to prevent and treat childhood obesity. Such lifestyle interventions have been supported by recent systematic reviews, ${ }^{12,13}$ as well as by the Canadian Paediatric Society, ${ }^{14}$ the Royal College of Paediatrics and Child Health, ${ }^{15}$ and the American Academy of Pediatrics. ${ }^{16}$ However, these interventions are fraught with poor adherence. ${ }^{17}$ Thus, school-based interventions are theoretically appealing because adherence with interventions can be improved. Consequently, many local governments have enacted or are considering policies that mandate increased physical activity in schools, ${ }^{18-22}$ although the effect of such interventions on body composition has not been assessed.

The objective of this study was to determine whether school-based physical activity interventions improve children's body composition, as measured by BMI.

\section{Methods}

\section{Literature search}

In collaboration with a professional librarian, we created individualized search strategies for 4 electronic databases: MEDLINE (January 1966 to September 2008), Cochrane CENTRAL Register of Controlled Trials (up to September 2008), EMBASE (January 1980 to September 2008) and CINAHL (January 1982 to September 2008). We searched the data-

From the Department of Pediatrics (Harris, Retallack), BC Children's Hospital; and the Centre for Clinical Epidemiology and Evaluation (Kuramoto, Schulzer), Vancouver General Hospital, Vancouver, BC 
bases for randomized controlled trials and nonrandomized clinical trials with an appropriate control group in which there was a school-based exercise or physical activity intervention. We did not apply a language restriction. We used the following MeSH terms: "obesity" or "overweight" and "schools" and "child" or "adolescent" and "exercise." A sample of the MEDLINE search strategy appears in Appendix 1 (available online at www.cmaj.ca/cgi/content/full/180/7/719/DC2). We also hand-searched the electronic versions of Pediatrics, the Journal of Pediatrics and the Archives of Pediatric and Adolescent Medicine from January 2003 through September 2008. We searched the reference lists of included articles and relevant reviews for additional eligible studies.

\section{Study selection}

Two authors (K.C.H. and J.E.R.) independently assessed the abstracts of potentially eligible studies. Controlled trials of a school-based exercise or physical activity intervention, in which the intervention took place during regular class time, were eligible for inclusion. The control group could not have received the intervention and must have continued with the existing physical education curriculum, with no change in duration or intensity. The participants had to have been of school age (5-18 years), and objective height and weight data demonstrating any change in BMI over the study period had to have been measured in both the intervention and control groups. The minimum study duration was 6 months. If there was doubt about study eligibility on the basis of information in the abstract, the reviewers examined the full text of the article. Discrepancies regarding study eligibility between the 2 reviewers were resolved by consensus. For studies that met the inclusion criteria but for which BMI data were incomplete, we contacted the authors and requested complete data for analysis. If we did not receive a response to the initial request, we sent a second request. We included studies without complete BMI data in the review but excluded them from the meta-analysis.

\section{Data extraction and validity assessment}

Two authors (K.C.H. and J.E.R.) independently extracted 4 categories of data from each included study: study design (randomized or nonrandomized study design and duration of study), population (grade level, ethnic origin, sex distribution, socio-economic status and numbers of children in the intervention and control groups) intervention (type and frequency of physical activity intervention and, in the case of mixed programs, data characterizing the type of co-intervention) and outcome (mean BMI and standard deviation in the intervention and control groups at baseline and follow-up and measures of physical activity). Where available, we also extracted data on other anthropometric measures of body composition, such as percent body fat, waist circumference, waist-to-hip ratio, triceps skin-fold thickness and subscapular skin-fold thickness.

We evaluated study quality using an assessment form designed specifically for this review based on the Jadad criteria ${ }^{23}$ and the Cochrane Effective Practice and Organisation of Care Review Group criteria. ${ }^{24}$ We based our quality assessment on the description of baseline characteristics, the method of randomization (for randomized controlled trials only), a priori power calculation, blinding of the outcome assessment, the description of the attrition rate and the description of the statistical analysis. Assigning a score to each study on the basis of individual scales does not provide a valid or comprehensive assessment of study quality. ${ }^{25}$ Therefore, we reported how each study rated on each criterion, as recommended in the most recent update of the Cochrane handbook. ${ }^{25}$

The 2 authors resolved discrepancies in data extraction and quality assessment by repeated review of the studies and discussion to reach consensus. If 2 or more articles presented data on the identical patient population, the BMI data were included only once in the meta-analysis.

\section{Data synthesis and analysis}

The primary outcome measure was mean change in BMI, calculated as mean BMI after intervention minus mean BMI before intervention. We selected BMI as the primary outcome measure because it has been shown to be a good measure of adiposity, it is superior to the $z$ score for BMI, and it is commonly measured and reported in studies assessing the effect of interventions for childhood obesity. ${ }^{26-29}$ For each study, we calculated the effect size as the difference in the mean change in BMI, as mean change in BMI in the intervention group minus mean change in BMI in the control group. For studies that reported the mean change in BMI with standard deviation, we used these values for the meta-analysis. For studies that reported BMI data before and after the intervention, we calculated the variance in the mean change in BMI, assuming a correlation coefficient of 0.9. We based this estimate on 2 studies in which standard deviation data were available for the mean pre-intervention BMI, mean postintervention BMI and mean change in BMI. ${ }^{30,31}$ We obtained a summary estimate for the difference in mean change in BMI, along with the $95 \%$ confidence interval (CI), using a weighted inverse variance approach and a random-effects model.

We used the $I^{2}$ statistic to assess the heterogeneity of summary estimates, ${ }^{32,33}$ where we considered a value greater than $50 \%$ as evidence of significant heterogeneity. We assessed the presence of publication bias using a funnel plot. We performed multiple 1-way sensitivity analyses to assess the robustness of the results. We performed a jackknife analysis, removing each study individually to assess its impact on the summary estimate. We also calculated the following summary estimates: studies that had co-interventions compared with studies that did not have cointerventions; studies that were longer than 1 year in duration compared with those up to 1 year in duration; studies with both boys and girls compared with those with only girls or only boys; and randomized controlled trials compared with controlled clinical trials. We also varied the correlation coefficient from 0.5 to 0.95 as part of the sensitivity analysis. For cluster controlled trials with measurements at the individual level but randomization at the school level, we examined the studies to ensure that clusteradjusted analyses had been performed. For trials in which it was unclear how this issue had been handled in the original study, we carried out appropriate cluster adjustments.

We collected data on other measures of body composition, if such data were available, but we did not perform metaanalyses because of insufficient reporting. Instead, we summarized these data descriptively. 


\section{Results}

\section{Literature search}

Using the search protocol, we identified 398 potentially relevant articles. Twenty-three of these studies met the inclusion criteria, but data were incomplete in 11 of them. We contacted the lead authors of these studies twice by email, and 8 of 11 of them provided additional data to allow metaanalysis. ${ }^{30,3440}$ Overall, 18 unique studies (from 23 articles) were available for inclusion in the analysis, and 15 of these studies were amenable to meta-analysis (Appendix 2, available online at www.cmaj.ca/cgi/content/full/180/7/719/DC2).

\section{Study characteristics}

The characteristics of the 18 studies $^{30,31,3449}$ are summarized in Appendix 3 (available online at www.cmaj.ca/cgi/content/full /180/7/719/DC2. Thirteen of the studies were randomized controlled trials $(n=13519)$, and 5 were controlled clinical trials $(n=4622)$. Twelve of the 13 randomized controlled trials were cluster trials, with randomization at the school level. In the 13th study, participants were randomized at the individual level. ${ }^{41}$ The type, duration and frequency of the physical activity intervention varied among the studies. Nine studies focused on increasing moderate to vigorous physical activity, 5 studies focused on increasing the time devoted to general physical activity, 2 studies implemented a new weight-bearing exercise, 1 study focused on activities using large muscle groups and 1 study introduced a physical education program personalized for each student (Appendix 3). Fifteen studies had some measure of physical activity. Of these, 5 studies used an objective measure: accelerometers in 2 studies $\mathrm{S}^{45,49}$ and the System for Observing Fitness Instruction Time (SOFIT) ${ }^{50}$ in 3 studies. ${ }^{31,46,48}$ Thirteen studies used questionnaires to assess levels of physical activity: 6 assessed total 24-hour physical activity, $35,38,40,43-45$ 5 assessed physical activity outside of school only, ${ }^{31,34,37,42,46}$ and 2 assessed physical activity both inside and outside of school. ${ }^{3,39}$ In 4 studies, adherence to the physical activity program was measured through teachers' logs of activities. ${ }^{43-45,49}$ No study objectively measured adherence to the physical activity program at the individual level.

Three studies consisted of only exercise interventions, and 15 studies had a co-intervention (Appendix 3). All cointerventions included a component of classroom nutrition or health education or family involvement. Twelve of the 15 studies with a co-intervention also promoted physical education through a modified classroom curriculum. The study duration ranged from 6 months to 3 years (median 18.5 months). Twelve studies were conducted in the United States, 3 in Canada and 1 in each of Australia, Chile and Sweden.

\section{Participant characteristics}

The analysis included a total of 18141 children. The majority of the children were in grades 3-6 (range: grades 1-12). Of the 13 studies that reported the participants' ethnicity, 7 involved primarily white populations. ${ }^{30,31,34,40,46,47,49}$ Six studies included only girls, ${ }^{35-38,43,49}$ and 1 study included only boys. ${ }^{44}$ In terms of baseline body composition, 16 studies sampled the general school population, 1 study gave preference to children with BMI at or above the 75th centile and decreased physical activity $^{37}$ and 1 study included only obese children. ${ }^{41}$

\section{Methodologic quality}

Overall, the included studies had relatively good quality of reporting (Appendix 4, available online at www.cmaj.ca/cgi/ content/full/180/7/719/DC2). Irrespective of randomization, the randomized controlled trials generally had a higher standard of reporting than the controlled clinical trials. Of the 13 randomized controlled trials, 4 studies clearly had the highest level of methodologic quality. ${ }^{31,43-45}$ Thirteen of the 18 studies reported the attrition rate. Only in the study by Kain and associates ${ }^{42}$ was there a significantly different attrition rate between the 2 groups: $9 \%$ in the intervention group and $21 \%$ in the control group.

\section{Change in body mass index}

The meta-analysis was conducted with 15 of the 18 studies. The following analyses, including the sensitivity analyses, refer to this subset of 15 studies. ${ }^{30,31,34,46}$

\section{Primary outcome}

The change in BMI was not significantly different between children who received a school-based physical activity intervention and those in the control group (weighted mean difference $-0.05 \mathrm{~kg} / \mathrm{m}^{2} ; 95 \% \mathrm{CI}-0.19$ to 0.10 ) (Figure 1). This indicates that body composition did not improve with physical activity. The result was statistically heterogeneous $\left(I^{2}=54 \%\right)$. The funnel plot showed no evidence of publication bias.

\section{Sensitivity analysis}

When only randomized controlled trials were included (12 studies, $n=8381$ ), the difference in change in BMI remained nonsignificant (weighted mean difference $0.01 \mathrm{~kg} / \mathrm{m}^{2}, 95 \%$ CI -0.14 to 0.14 ), but, notably, there was no longer significant statistical heterogeneity $\left(I^{2}=19 \%\right)$ (Figure 2$)$. The presence of a co-intervention did not affect the summary estimate. Specifically, the change in BMI for those who received a cointervention in addition to the physical activity intervention was not significantly different from that of control children (weighted mean difference $-0.08 \mathrm{~kg} / \mathrm{m}^{2}, 95 \% \mathrm{CI}-0.22$ to 0.07). Similarly, the duration of the study did not affect the results significantly. For studies that lasted up to 1 year, the weighted mean difference was $-0.09 \mathrm{~kg} / \mathrm{m}^{2}(95 \% \mathrm{CI}-0.29$ to 0.12 ). This was not significantly different from the weighted mean difference for studies that lasted longer than 1 year (weighted mean difference $0.00 \mathrm{~kg} / \mathrm{m}^{2}, 95 \% \mathrm{CI}-0.21$ to 0.21 ). We also compared the highest-quality studies with the lowerquality studies to determine whether study quality influenced the results. The weighted mean difference for high-quality studies was $-0.08 \mathrm{~kg} / \mathrm{m}^{2}$ (95\% CI -0.35 to 0.19$)$, which indicates that variance in study quality had no effect on the results. We assessed sex-related data to determine whether there was a different response for boys and girls. The single study involving only boys did not show a significant change in BMI. The weighted mean difference for studies involving only girls was $-0.02 \mathrm{~kg} / \mathrm{m}^{2}$ ( $95 \% \mathrm{CI}-0.30$ to 0.27 ). The weighted mean difference for studies involving both boys and girls was $-0.07 \mathrm{~kg} / \mathrm{m}^{2}(95 \%-0.25$ to 0.10 ). Sex did not influence the results of the meta-analysis, al- 
though there was only 1 study that involved only boys.

The jackknife analysis did not change the results significantly. Interestingly, removal of the study by Spiegel and Foulk $^{39}$ ( 1 of the 5 controlled clinical trials) eliminated the statistical heterogeneity $\left(I^{2}=24 \%\right)$, although the summary estimate of change in BMI was unchanged (weighted mean difference $-0.01 \mathrm{~kg} / \mathrm{m}^{2}, 95 \% \mathrm{CI}-0.12$ to 0.11$)$. No other single study had a significant effect on the summary estimate or the statistical heterogeneity.

We obtained our summary estimate using an estimated correlation coefficient of 0.9 in studies that reported preintervention and post-intervention BMI data $(n=9)$. Varying the correlation coefficient from 0.5 (weighted mean difference $-0.04 \mathrm{~kg} / \mathrm{m}^{2}, 95 \% \mathrm{CI}-0.22$ to 0.13 ) to 0.95 (weighted mean difference $-0.05 \mathrm{~kg} / \mathrm{m}^{2}, 95 \% \mathrm{CI}-0.18$ to 0.09 ) did not change the summary estimate significantly.

Ten of 15 studies clearly described appropriate clusteradjusted analyses ${ }^{31,34-38,40,42,45}$ or did not require cluster adjustment. ${ }^{41}$ In the 5 studies where the analysis was less clearly described, we performed appropriate cluster adjustments. . $^{30,39,43,44,46}$
The weighted mean difference using these additional cluster adjustments was $-0.05 \mathrm{~kg} / \mathrm{m}^{2}$ (95\% CI -0.18 to 0.08 ).

Three studies reported BMI data that were not amenable to meta-analysis (Table 1). In 2 of these 3 studies, there was no significant change in BMI with the intervention. ${ }^{48,49}$ The third study reported that BMI increased more in girls with the physical activity intervention, but there was no significant change in boys. ${ }^{47}$

\section{Change in other measures of body composition}

Ten studies presented at least one other measure of body composition in addition to BMI. Outcome measures reported included percent body fat, waist circumference, waist-to-hip ratio, triceps skin-fold thickness, subscapular skin-fold thickness, total lean mass, total fat mass and skin-fold sum. Only 3 of the 18 reported comparisons demonstrated significant improvement with physical activity intervention, ${ }^{41,42,44} 1$ demonstrated deterioration with physical activity intervention, ${ }^{46}$ and 14 did not show any significant change (Table 1). None of the 3 outcomes with improvements in body composition were associated with improved BMI. ${ }^{41,42,44}$

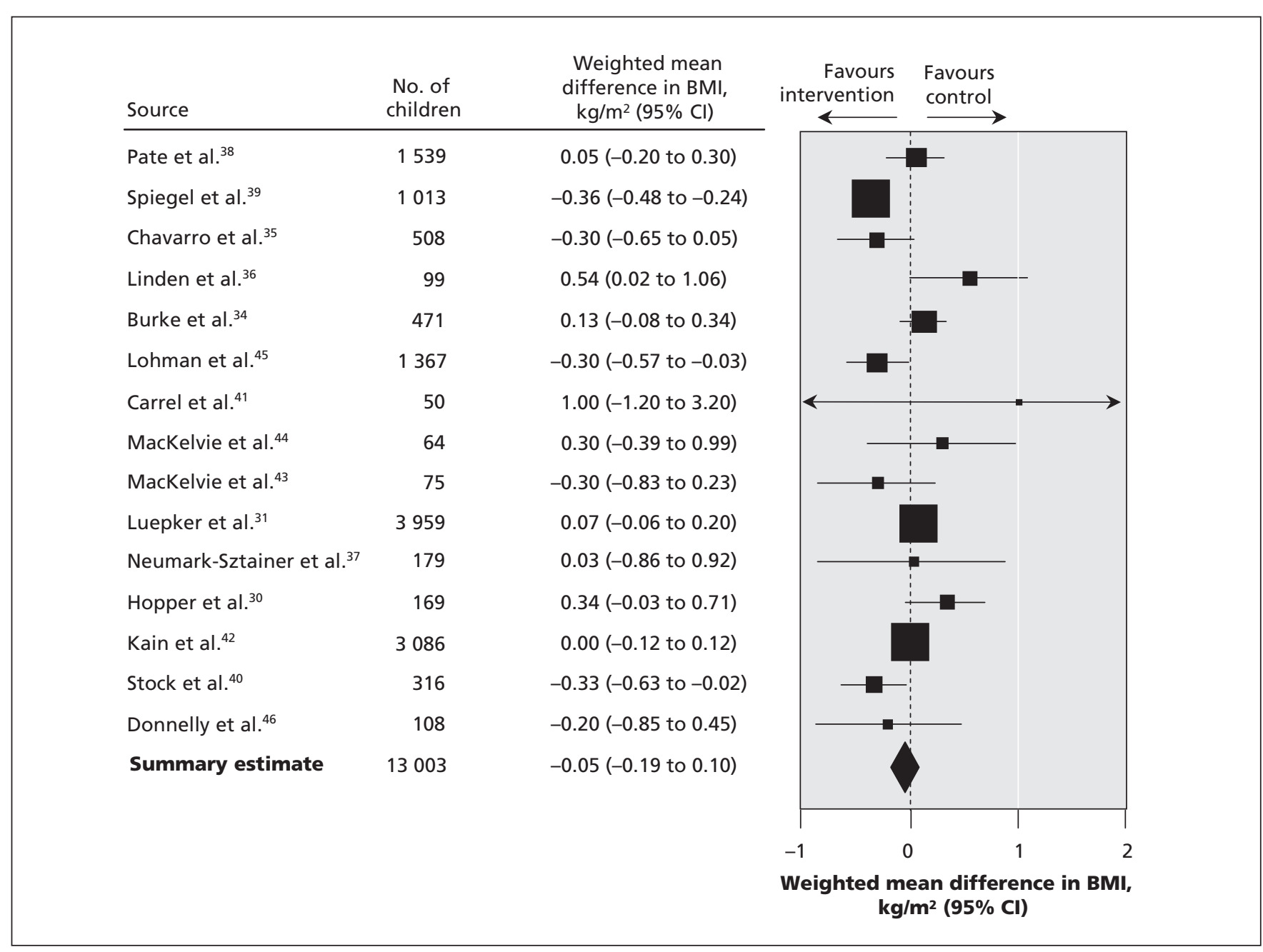

Figure 1: Weighted mean difference in change in body mass index (BMI) between the intervention group (school-based physical activity) and the control group. The size of each data marker indicates the weight assigned to the individual study. These weights are proportional to the inverse of the variance for each study. Larger studies tend to have less variance (because of sample size) and therefore receive more weight. Note: $\mathrm{Cl}=$ confidence interval. 


\section{Interpretation}

Our meta-analysis indicated that school-based physical activity interventions did not improve BMI. Therefore, such interventions are unlikely to have a significant effect on the increasing prevalence of childhood obesity. Our inferences appeared consistent among the many secondary analyses that we performed. Variation in the duration, intensity and structure of school-based physical activity interventions had minimal effects on short-term or long-term BMI change. The consistency of the BMI results among the studies included in the meta-analysis was striking $(r=0.97)$. This finding is important for policy-makers who continue to promote schoolbased physical activity as a central component of the strategy to reduce childhood obesity. ${ }^{19-22,51}$

Whereas other authors have suggested that physical activity interventions may be ineffective in improving body composition in children, ${ }^{12}$ our study provides quantitative evidence for this conclusion. Although the physical activity interventions in the studies we analyzed were not successful in improving BMI, the underlying reasons for failure were unclear. It is possible that the "dose" of physical activity achieved in these studies was insufficient to improve BMI, either because of the quantity of physical activity in the intervention or the adherence of individual children to the intervention. Only 5 of the 18 studies had objective measures of physical activity. In the 3 studies in which physical activity was compared with the SOFIT instrument, there was more physical activity in the intervention group than the control group. However, both
Lohman and associates ${ }^{45}$ and Webber and colleagues ${ }^{49}$ used accelerometers and found no difference in physical activity between the intervention and control groups. Notably, all of these objective measures were used for only a short segment of the study protocol. None of the studies measured adherence to the intervention at the individual level, and only 4 studies measured adherence at the school level. A second possibility is that there may have been a small effect in a subset of children, but the effect was attenuated in the assessment of the entire population. For example, it is plausible that children with higher baseline BMI would benefit more from such interventions. Conversely, children with higher BMI may have lower levels of adherence. As a consequence, they would benefit less from such interventions. A third possibility is that physical activity may have relatively little influence on body composition compared with dietary intake.

The association between reduced physical activity and obesity has been well established. ${ }^{52,53}$ However, there is no conclusive evidence that reduced physical activity is a causal component in the pathway leading to childhood obesity. Rather, there is evidence to suggest that the observed association may be a downstream effect of obesity. ${ }^{54,55}$ Specifically, a prospective study demonstrated that increased BMI predicts a decline in physical activity, ${ }^{54}$ and another recent study demonstrated that improvements in body composition may be attained through dietary change rather than physical activity. ${ }^{55}$ A better understanding of the causal pathway leading to childhood obesity may facilitate the development of new interventions that will improve body composition.

\begin{tabular}{|c|c|c|c|c|}
\hline Study characteristic & $\begin{array}{l}\text { No. of } \\
\text { children }\end{array}$ & $\begin{array}{l}\text { Weighted mean } \\
\text { difference in } \mathrm{BMI} \text {, } \\
\mathrm{kg} / \mathrm{m}^{2}(95 \% \mathrm{Cl})\end{array}$ & $\begin{array}{r}\text { Favours } \\
\text { intervention } \\
\longleftarrow\end{array}$ & $\begin{array}{l}\text { Favours } \\
\text { control }\end{array}$ \\
\hline Randomized controlled trials & 8381 & $0.01(-0.14$ to 0.14$)$ & & \\
\hline Study duration $\leq 1 \mathrm{yr}$ & 6654 & $-0.09(-0.29$ to 0.12$)$ & & \\
\hline Study duration $>1 \mathrm{yr}$ & 6349 & $0.00(-0.21$ to 0.21$)$ & & \\
\hline High-quality studies & 5465 & $-0.08(-0.35$ to 0.19$)$ & & \\
\hline Girls only & 2400 & $-0.02(-0.30$ to 0.27$)$ & & \\
\hline & & & -1 & 1 \\
\hline \multicolumn{5}{|c|}{$\begin{array}{l}\text { Weighted mean difference in BMI, } \\
\mathrm{kg} / \mathrm{m}^{2}(95 \% \mathrm{Cl})\end{array}$} \\
\hline
\end{tabular}

Figure 2: Sensitivity analysis for weighted mean difference in change in body mass index (BMI) between the intervention group (school-based physical activity) and the control group. Note: $\mathrm{Cl}=$ confidence interval. 


\section{Limitations}

Our meta-analysis showed that school-based physical activity interventions did not improve BMI, but there are limitations to BMI as a measure of body composition. BMI reflects both fat and fat-free components of body weight. ${ }^{56}$ Populations may vary with respect to relative amounts of lean muscle mass and body fat. Furthermore, the distribution of body fat may vary among individuals or populations, which can have important prognostic significance. It is possible that schoolbased physical activity could increase lean muscle mass and decrease fat mass with no overall change in BMI.

Other measures of body composition have been suggested, such as waist circumference, skin-fold thickness and percent body fat, and all of these warrant investigation. ${ }^{57-59}$ However, BMI is the most consistently reported measure of body composition, ${ }^{56}$ which makes it amenable to meta-analysis. It is our view that $\mathrm{BMI}$ is an important outcome measure, as the links between elevated BMI and adverse health outcomes have been clearly established. In adults, an elevated BMI is associated with increased rates of diabetes mellitus, heart disease, cancer and death. ${ }^{60-62}$ Similarly, elevated BMI in children is associated with increased blood pressure, hyperlipidemia and type 2 diabetes, as well as development of coronary artery disease and increased all-cause mortality later in life..$^{1,63-66}$ Children with elevated BMI are at high risk of having elevated BMI as adults. ${ }^{67}$ Future studies should continue to focus

Table 1: Effect of school-based physical activity on measures of body composition

\begin{tabular}{|c|c|c|c|c|}
\hline Measure of body composition & $\begin{array}{l}\text { No. of } \\
\text { children }\end{array}$ & $\begin{array}{l}\text { Outcome in intervention } \\
\text { group relative to control }\end{array}$ & $\begin{array}{l}\text { Difference in mean } \\
\text { change* }(95 \% \mathrm{Cl})\end{array}$ & $p$ valuet \\
\hline \multicolumn{5}{|l|}{$\%$ body fat } \\
\hline Lohman et al. ${ }^{45}$ & 1367 & No difference & $0.2 \%(-0.84 \%$ to $1.31 \%)$ & 0.66 \\
\hline Carrel et al. ${ }^{41}$ & 50 & Decreased & $-2.0 \%$ & 0.04 \\
\hline Donnelly et al. ${ }^{46}$ & 108 & Increased & $+1.3 \%$ & Not reported \\
\hline \multicolumn{5}{|l|}{ Triceps skin-fold } \\
\hline Lohman et al. ${ }^{45}$ & 1367 & No difference & $0.1 \mathrm{~mm}(-0.67$ to 0.83$)$ & 0.84 \\
\hline Luepker et al. ${ }^{31}$ & 3959 & No difference & $+0.1 \mathrm{~mm}$ & 0.70 \\
\hline \multirow[t]{2}{*}{ Kain et al. ${ }^{42}$} & 3086 & Boys: no difference & $+0.3 \mathrm{~mm}$ & 0.14 \\
\hline & & Girls: no difference & $-0.3 \mathrm{~mm}$ & 0.35 \\
\hline \multicolumn{5}{|l|}{ Subscapular skin-fold } \\
\hline Lohman et al. ${ }^{45}$ & 1367 & No difference & $-0.1 \mathrm{~mm}(-0.85$ to 0.70$)$ & 0.85 \\
\hline Luepker et al. ${ }^{31}$ & 3959 & No difference & $+0.1 \mathrm{~mm}$ & 0.64 \\
\hline \multicolumn{5}{|l|}{ Total lean mass } \\
\hline MacKelvie et al. ${ }^{43}$ & 75 & No difference & $-0.3 \mathrm{~kg}$ & $>0.01$ \\
\hline MacKelvie et al. ${ }^{44}$ & 64 & Increased & $1.267 \mathrm{~kg}$ & $<0.05$ \\
\hline \multicolumn{5}{|l|}{ Total fat mass } \\
\hline MacKelvie et al. ${ }^{43}$ & 75 & No difference & $-0.7 \mathrm{~kg}$ & $>0.01$ \\
\hline MacKelvie et al. ${ }^{44}$ & 64 & No difference & $-0.367 \mathrm{~kg}$ & $>0.05$ \\
\hline \multicolumn{5}{|l|}{ Waist circumference } \\
\hline \multirow[t]{2}{*}{ Kain et al. $^{42}$} & 3086 & Girls: no difference & $-0.3 \mathrm{~cm}$ & 0.18 \\
\hline & & Boys: decreased & $-1.8 \mathrm{~cm}$ & $<0.001$ \\
\hline \multicolumn{5}{|l|}{ Skin-fold sum } \\
\hline Hopper et al. ${ }^{30}$ & 169 & No difference & $-0.18 \mathrm{~mm}$ & $>0.05$ \\
\hline Sallis et al. ${ }^{47}$ & 740 & Boys and girls: no difference & Not reported & $>0.05$ \\
\hline \multicolumn{5}{|l|}{ Waist-to-hip ratio } \\
\hline Coleman et al. ${ }^{48}$ & 896 & No difference & Not reported & Not reported \\
\hline \multicolumn{5}{|l|}{ Body mass index‡ } \\
\hline \multirow[t]{2}{*}{ Sallis et al. ${ }^{47}$} & 740 & Boys: no difference & Not reported & $>0.05$ \\
\hline & & Girls: increased & Not reported & $<0.01$ \\
\hline Webber et al. ${ }^{49}$ & 3502 & No difference & 0 & Not reported \\
\hline Coleman et al. ${ }^{48}$ & 896 & No difference & Not reported & Not reported \\
\hline
\end{tabular}

Note: $\mathrm{Cl}=$ confidence interval.

*Intervention minus control.

†As reported in original articles.

‡Data not amenable to meta-analysis. 
on improving BMI, given the recent dramatic increases in BMI across the entire population of children and the clear links between elevated BMI and adverse health outcomes. ${ }^{68}$

We are concerned that these results may have a negative impact on the promotion of physical activity in schools. From a public health perspective, school-based physical activity is important, because of the significant health benefits that have been demonstrated. These include reducing blood pressure, ${ }^{69}$ increasing lean muscle mass, ${ }^{43}$ increasing bone mineral density, ${ }^{36,43,44}$ increasing aerobic capacity ${ }^{41,52}$ and improving flexibility. ${ }^{52}$ It is therefore important to promote school-based physical activity for its demonstrated health benefits, even though there is currently no evidence that it is an effective method to reverse the trend of increasing BMI in children. The results of this metaanalysis may help to clarify the goals of government policies.

We included both randomized controlled trials and controlled clinical trials in our study because we recognized the inherent difficulties in engaging schools in randomized controlled trials. The summary estimate and confidence interval that we obtained from our meta-analysis of the randomized controlled trials, which represent the gold standard for metaanalysis, ${ }^{70}$ were remarkably similar to those obtained from all studies. Importantly, there was no significant statistical heterogeneity among the randomized controlled trials.

Our analysis may be limited by variation among the studies. The most significant source of variation among studies was the range of physical activity interventions implemented. Each of the 18 physical activity interventions included in the analysis was completed as a component of a research protocol and may have received more intensive support than would be possible in the typical school environment. Given that these studies were not efficacious, it is unlikely that such interventions would be effective if widely implemented through changes in policy.

The 2 main limitations observed in the primary studies were lack of assessment of adherence to study protocols, both at the school level and at the individual level, and lack of objective assessment of the "dose" of physical activity achieved with such interventions. Future studies should address these issues. We believe that a well-conducted cluster randomized controlled trial should be of sufficient duration to allow observation of clinically important changes in body composition and should be designed with enough students to detect small but meaningful changes in BMI. Based upon our results and those of previous studies it appears that if there is a positive effect of school-based physical activity on BMI, the effect size is likely small. Therefore, having a study that is appropriately powered is critical. ${ }^{12}$ Finally, in addition to collecting appropriate anthropometric data, future studies should also assess the impact of such interventions on the metabolic profile of children.

\section{Conclusion}

Physical activity should be included and promoted within schools, as it is an important component of a healthy lifestyle and improves many aspects of health. ${ }^{15,71,72}$ However, our metaanalysis has shown that school-based physical activity interventions do not improve body composition. Further studies that improve on previous methodologic weakness are required before widespread promotion of school-based physical activity as a central component of the solution for childhood obesity. Should such policies be implemented before further study, they should be part of a research protocol. Multiple interventions that target different aspects in the causal pathway may be more successful in improving children's body composition. Interventions that aim to improve diet have shown promise in improving BMI. ${ }^{73-76}$ Effective interventions should be pursued, and the school setting is an important setting in which to initiate change.

This article has been peer reviewed.

Competing interests: None declared.

Contributors: Kevin Harris participated in the study concept and design, the acquisition, analysis and interpretation of data, and the drafting and critical revision of the manuscript. Jennifer Retallack participated in the acquisition, analysis and interpretation of data and in drafting and critical revision of the manuscript. Kevin Harris and Jennifer Retallack had full access to all of the data in the study and take responsibility for the integrity of the data and the accuracy of the data analysis. Lisa Kuramoto participated in the analysis and interpretation of the data, the statistical analysis of the study and critical revision of the manuscript. Michael Schulzer participated in the analysis and interpretation of the data, the statistical analysis of the study and critical revision of the manuscript. Each of the authors saw and approved the final version of the manuscript.

Acknowledgements: We thank Steven P. Miller MD and Shubhayan Sanatani MD, BC Children's Hospital, Vancouver, British Columbia, for their helpful presubmission review of the manuscript, for which they received no compensation.

Funding: There was no funding source for this study.

\section{REFERENCES}

1. Reilly JJ, Methven E, McDowell ZC, et al. Health consequences of obesity. Arch Dis Child 2003;88:748-52.

2. Ogden CL, Flegal KM, Carroll MD, et al. Prevalence and trends in overweight among US children and adolescents, 1999-2000. JAMA 2002;288:1728-32.

3. Ogden CL, Carroll MD, Curtin LR, et al. Prevalence of overweight and obesity in the United States, 1999-2004. JAMA 2006;295:1549-55.

4. Shields M. Overweight Canadian children and adolescents. Ottawa (ON): Statistics Canada; 2005 [modified 2008 Nov. 16]. Available: www.statcan.ca/english/research /82-620-MIE/2005001/articles/child/cobesity.htm (accessed 2009 Jan. 16)

5. Jotangia D, Moody A, Stamatakis E, et al.; National Centre for Social Research, Department of Epidemiology and Public Health at the Royal Free and University College Medical School. Obesity among children under 11 [revised]. London (UK): UK Department of Health; 2006. Available: www.dh.gov.uk/en/Publicationsand statistics/Publications/PublicationsStatistics/DH 4109245 (accessed 2009 Jan. 16).

6. Rolland-Cachera MF, Castetbon K, Arnault N, et al. Body mass index in 7-9-y-old French children: frequency of obesity, overweight and thinness. Int J Obes Relat Metab Disord 2002;26:1610-6.

7. Fredriks AM, van Buuren S, Wit JM, et al. Body index measurements in 1996-7 compared with 1980. Arch Dis Child 2000;82:107-12.

8. Bibbins-Domingo K, Coxson P, Pletcher MJ, et al. Adolescent overweight and future adult coronary heart disease. $N$ Engl J Med 2007;357:2371-9.

9. Hayman LL, Williams CL, Daniels SR, et al. Cardiovascular health promotion in the schools: a statement for health and education professionals and child health advocates from the committee on atherosclerosis, hypertension, and obesity in youth (AHOY) of the Council on Cardiovascular Disease in the Young, American Heart Association. Circulation 2004;110:2266-75.

10. Sorof JM, Lai D, Turner J, et al. Overweight, ethnicity, and the prevalence of hypertension in school-aged children. Pediatrics 2004;113:475-82.

11. Olshansky SJ, Passaro DJ, Hershow RC, et al. A potential decline in life expectancy in the United States in the 21st century. N Engl J Med 2005;352:1138-45.

12. Summerbell CD, Waters E, Edmunds LD, et al. Interventions for preventing obesity in children. Cochrane Database Syst Rev 2005;(3):CD001871.

13. Epstein LH, Goldfield GS. Physical activity in the treatment of childhood overweight and obesity: current evidence and research issues. Med Sci Sports Exerc 1999;31(11 Suppl):S553-9.

14. Advisory Committee on Healthy Active Living for Children and Youth. Healthy active living for children and youth. Paediatr Child Health 2002;7:339-45.

15. Gibson P, Edmunds L, Haslam DW, et al. An approach to weight management in children and adolescents (2-18 years) in primary care. London (UK): Royal College of Paediatrics and Child Health; 2002. Available: www.tripdatabase.com /SearchLander.html?s=1\&gk=An+approach+to+weight+management+in+children +and+adolescents+\% $282 \% \mathrm{E} 2 \% 80 \% 9318 \mathrm{yrs} \% 29+\mathrm{in}+$ primary+care\&itemId=324384 (accessed 2009 Jan. 16).

16. Committee on Nutrition. Prevention of pediatric overweight and obesity. Pediatrics 2003;112:424-30. 
17. Peterson KE, Fox MK. Addressing the epidemic of childhood obesity through school-based interventions: What has been done and where do we go from here? $J$ Law Med Ethics 2007;35:113-30.

18. Are we doing enough? A status report on Canadian public policy and child and youth health. Ottawa (ON): Canadian Pediatric Society; 2007. Available: www.cps .ca/English/Advocacy/StatusReport07.pdf (accessed 2009 Jan. 16).

19. Childhood obesity - 2006 update and overview of policy options. Denver (CO): National Conference of State Legislatures; 2007. Available: www.ncsl.org/programs /health/ChildhoodObesity-2006.htm (accessed 2009 Jan. 16).

20. A strategy for combatting childhood obesity and physical inactivity in British Columbia. Victoria (BC): Legislative Assembly of British Columbia, Select Standing Committee on Health; 2006. Available: www.leg.bc.ca/cmt/38thparl/session-2 /health/reports/Rpt-Health-38-2-29Nov2006.pdf (accessed 2009 Jan. 16).

21. Choosing activity: a physical activity action plan. London (UK): Department of Health; 2005. Available: www.dh.gov.uk/en/Publicationsandstatistics/Publications/PublicationsPolicyAndGuidance/DH_4105354 (accessed 2009 Mar. 2).

22. The action plan on physical activity 2005-2009; working together for physical activity. Oslo (Norway): Norwegian Ministry of Health and Care Services; 2005. Available: www.regjeringen.no/upload/kilde/hod/red/2006/0002/ddd/pdfv/269037-hod kortversjon engelsk.pdf (accessed 2009 Jan. 16)

23. Jadad AR, Moore RA, Carroll D, et al. Assessing the quality of reports of randomized clinical trials: Is blinding necessary? Control Clin Trials 1996;17:1-12.

24. Data collection checklist. Ottawa $(\mathrm{ON})$ : Cochrane Effective Practice and Organisation of Care Review Group (EPOC); 2002. Available: http://epoc.cochrane.org /Files/Website/Reviewer\%20Resources/Data\%20Collection\%20Checklist\%20-\%20 EPOC\%20-\%202007-Feb-27.doc (accessed 2009 Jan. 16)

25. Higgins J, Altman D. Assessing risk of bias in included studies. In: Higgins JPT, Green S, editors. Cochrane handbook for systematic reviews of interventions. Version 5.0.1. Cochrane Collaboration; 2008. Available: www.cochrane-handbook.org (accessed 2009 Jan. 16).

26. Dietz WH, Robinson TN. Use of the body mass index (BMI) as a measure of overweight in children and adolescents. J Pediatr 1998;132:191-3.

27. Mei Z, Grummer-Strawn LM, Wang J, et al. Do skinfold measurements provide additional information to body mass index in the assessment of body fatness among children and adolescents? Pediatrics 2007;119:e1306-13

28. Pietrobelli A, Faith MS, Allison DB, et al. Body mass index as a measure of adiposity among children and adolescents: a validation study. J Pediatr 1998;132:204-10.

29. Cole TJ, Faith MS, Pietrobelli A, et al. What is the best measure of adiposity change in growing children: BMI, BMI \%, BMI z-score or BMI centile? Eur J Clin Nutr 2005:59:419-25.

30. Hopper CA, Munoz KD, Gruber MB, et al. The effects of a family fitness program on the physical activity and nutrition behaviors of third-grade children. Res $Q E x$ erc Sport 2005;76:130-9.

31. Luepker RV, Perry CL, McKinlay SM, et al. Outcomes of a field trial to improve children's dietary patterns and physical activity: the Child and Adolescent Trial for Cardiovascular Health (CATCH). JAMA 1996;275:768-76.

32. Higgins JPT, Thompson SG, Deeks JJ, et al. Measuring inconsistency in metaanalyses. BMJ 2003;327:557-60.

33. Higgins JPT, Thompson SG. Quantifying heterogeneity in a meta-analysis. Stat Med 2002;21:1539-58.

34. Burke V, Milligan RA, Thompson C, et al. A controlled trial of health promotion programs in 11-year-olds using physical activity "enrichment" for higher risk children. J Pediatr 1998;132:840-8.

35. Chavarro JE, Peterson KE, Sobol AM, et al. Effects of a school-based obesityprevention intervention on menarche (United States). Cancer Causes Control 2005; $16: 1245-52$.

36. Linden C, Ahlborg HG, Besjakov J, et al. A school curriculum-based exercise program increases bone mineral accrual and bone size in prepubertal girls: two-year data from the Pediatric Osteoporosis Prevention (POP) study. J Bone Miner Res 2006;21:829-35.

37. Neumark-Sztainer D, Story M, Hannan PJ, et al. New moves: a school-based obesity prevention program for adolescent girls. Prev Med 2003;37:41-51.

38. Pate RR, Ward DS, Saunders RP, et al. Promotion of physical activity among highschool girls: a randomized controlled trial. Am J Public Health 2005:95:1582-7.

39. Spiegel SA, Foulk D. Reducing overweight through a multidisciplinary schoolbased intervention. Obesity (Silver Spring) 2006;14:88-96.

40. Stock S, Miranda C, Evans S, et al. Healthy buddies: a novel, peer-led health promotion program for the prevention of obesity and eating disorders in children in elementary school. Pediatrics 2007;120:e1059-68.

41. Carrel AL, Clark RR, Peterson SE, et al. Improvement of fitness, body composition, and insulin sensitivity in overweight children in a school-based exercise program: a randomized, controlled study. Arch Pediatr Adolesc Med 2005;159:963-8.

42. Kain J, Uauy R, Albala, et al. School-based obesity prevention in Chilean primary school children: methodology and evaluation of a controlled study. Int J Obes Relat Metab Disord 2004;28:483-93.

43. MacKelvie KJ, Khan KM, Petit MA, et al. A school-based exercise intervention elicits substantial bone health benefits: a 2-year randomized controlled trial in girls. Pediatrics 2003;112:e447.

44. MacKelvie KJ, Petit MA, Khan KM, et al. Bone mass and structure are enhanced following a 2-year randomized controlled trial of exercise in prepubertal boys. Bone 2004:34:755-64.

45. Lohman T, Thompson J, Going S, et al. Indices of changes in adiposity in American Indian children. Prev Med 2003;37:S91-6.

46. Donnelly JE, Jacobsen D, Whatley J, et al. Nutrition and physical activity program to attenuate obesity and promote physical and metabolic fitness in elementary school children. Obes Res 1996;4:229-43.

47. Sallis JF, McKenzie TL, Alcaraz JE, et al. Project SPARK. Effects of physical education on adiposity in children. Ann N Y Acad Sci 1993;699:127-36.

48. Coleman KJ, Tiller C, Sanchez J, et al. Prevention of the epidemic of overweight in low-income schools. Arch Pediatr Adolesc Med 2005:159:217-24.

49. Webber LS, Catellier DJ, Lytle LA, et al. Promoting physical activity in middle school girls: Trial of Activity for Adolescent Girls. Am J Prev Med 2008;34:173-184

50. Pope RP, Coleman KJ, Gonzalez EC, et al. Validity of revised System for Observing Fitness Instruction Time (SOFIT). Pediatr Exerc Sci 2002;14:135-46.

51. Canadian Association of Pediatric Health Centres; Pediatric Chairs of Canada; CIHR Institute of Nutrition, Metabolism and Diabetes. Addressing childhood obesity: a call for action. Ottawa (ON): Canadian Institutes of Health Research; 2004.

52. Kahn EB, Ramsey LT, Brownson RC, et al. The effectiveness of interventions to increase physical activity. A systematic review. Am J Prev Med 2002;22(4 Suppl); 73-107.

53. Trost SG, Kerr LM, Ward DS, et al. Physical activity and determinants of physical activity in obese and non-obese children. Int J Obes Relat Metab Disord 2001;25:822-9.

54. Kimm SYS, Glynn NW, Kriska AM, et al. Decline in physical activity in black girls and white girls during adolescence. N Engl J Med 2002;347:709-15.

55. Jakicic JM, Marcus BH, Gallagher KI, et al. Effect of exercise duration and intensity on weight loss in overweight, sedentary women: a randomized trial. JAMA 2003;290:1323-30

56. Sweeting HN. Measurement and definitions of obesity in childhood and adolescence: a field guide for the uninitiated. Nutr $J$ 2007;6:32

57. Bray GA, DeLany JP, Volaufova J, et al. Prediction of body fat in 12-y-old African American and white children: evaluation of methods. Am J Clin Nutr 2002;76:980-90.

58. McCarthy HD. Body fat measurements in children as predictors for the metabolic syndrome: focus on waist circumference. Proc Nutr Soc 2006;65:385-92.

59. Wells JCK. A critique of the expression of paediatric body composition data. Arch Dis Child 2001;85:67-72.

60. Calle EE, Thun MJ, Petrelli JM, et al. Body-mass index and mortality in a prospective cohort of US adults. N Engl J Med 1999;341:1097-105

61. Jee SH, Sull JW, Park J, et al. Body-mass index and mortality in Korean men and women. N Engl J Med 2006;355:779-87.

62. Mora S, Yanek LR, Moy TF, et al. Interaction of body mass index and Framing ham risk score in predicting incident coronary disease in families. Circulation 2005; 111:1871-6.

63. Must A, Jacques P, Dallal G, et al. Long-term morbidity and mortality of overweight adolescents. A follow-up of the Harvard growth study of 1922 to 1935 . N Engl J Med 1992;327:1350-5.

64. Must A, Strauss RS. Risks and consequences of childhood and adolescent obesity. Int J Obes Relat Metab Disord 1999;23 Suppl 2:S2-11

65. Freedman DS, Dietz WH, Srinivasan SR, et al. The relation of overweight to cardiovascular risk factors among children and adolescents: the Bogalusa heart study. Pediatrics 1999;103:1175-82.

66. Din-Dzietham R, Liu Y, Bielo MV, et al. High blood pressure trends in children and adolescents in national surveys, 1963 to 2002. Circulation 2007:116:1488-96.

67. Whitaker RC, Wright JA, Pepe MS, et al. Predicting obesity in young adulthood from childhood and parental obesity. N Engl J Med 1997;337:869-73.

68. Tremblay MS, Willms JD. Secular trends in the body mass index of Canadian children. CMAJ 2000;163:1429-33

69. Hansen HS, Froberg K, Hyldebrandt N, et al. A controlled study of eight months of physical training and reduction of blood pressure in children: the Odense schoolchild study. BMJ 1991;303:682-5

70. Schünemann HJ, Oxman AD, Vist GE, et al. Interpreting results and drawing conclusions. In: Higgins JPT, Green S, editors. Cochrane handbook for systematic reviews of interventions. Version 5.0.1. Cochrane Collaboration; 2008. Available: www.cochrane-handbook.org (accessed 2009 Mar.3).

71. Council on Sports Medicine and Fitness; Council on School Health. Active healthy living: prevention of childhood obesity through increased physical activity. Pediatrics 2006; 117:1834-42.

72. Pate RR, Davis MG, Robinson TN, et al. Promoting physical activity in children and youth: a leadership role for schools: a scientific statement from the American Heart Association Council on Nutrition, Physical Activity, and Metabolism (Physical Activity Committee) in collaboration with the Councils on Cardiovascular Disease in the Young and Cardiovascular Nursing. Circulation 2006;114:1214-24.

73. Epstein LH, Roemmich JN, Robinson JL, et al. A randomized trial of the effects of reducing television viewing and computer use on body mass index in young children. Arch Pediatr Adolesc Med 2008;162:239-45.

74. James J, Thomas P, Cavan D, et al. Preventing childhood obesity by reducing consumption of carbonated drinks: cluster randomised controlled trial. BMJ 2004 328:1237.

75. Foster GD, Sherman S, Borradaile KE, et al. A policy-based school intervention to prevent overweight and obesity. Pediatrics 2008;121:e794-802

76. Collins CE, Warren J, Neve M, et al. Measuring effectiveness of dietetic interventions in child obesity: a systematic review of randomized trials. Arch Pediatr Adolesc Med 2006;160:906-22.

Correspondence to: Dr. Kevin C. Harris, Department of Pediatrics, BC Children's Hospital, 4480 Oak St., Vancouver BC V6H3V4; kharris2@cw.bc.ca 